\title{
Synthetic Information Ore-prospecting Model for Gold Copper Minerals of East Yanbian Area
}

\author{
Yanying $\mathrm{Ma}^{1}$ and Enyang $\mathrm{Gao}^{2, *}$ \\ 'Jilin Engineering Normal University Changchun, China, 130052 \\ ${ }^{2}$ Shenyang Jianzhu University, Shenyang, China \\ 1060138576@qq.com \\ *The corresponding author
}

Keywords: East Yanbian area; Multi-source information; Ore-prospecting model

\begin{abstract}
The authors analyzed the relationship between gold copper mine and geological conditions strata, magmatic rocks, structure, etc. and identified the control action of various geological conditions to gold copper mine base on previous research results and taking the gold copper mine in East Yanbian district of Jilin province as the prediction mine type and the gold copper deposit as the target . Find out all kinds of geological conditions on gold, copper mineral control action of and control method. At the same time, the authors have established the synthetic information ore-prospecting model in Yanbian area of Jilin province.
\end{abstract}

\section{Introduction}

The discussion is taken in East Yanbian Korean Autonomous Prefecture, Jilin province, where the earth structure is divided into units and is one of the most important regions rich in gold and multi-mineral metallogenic belt. In the researching area, there are great varieties of minerals including the main deposits copper, gold, lead, zinc, Tungsten, molybdenum, iron and so on, among which, gold-copper minerals are important mines. Many known gold-copper mines are of great importance in locating and applying mines.

\section{Geological Background of the Region}

This region experienced two structural developing processes, they are ancient Asia and approching Pacific Ocean structural region, where the later one is main and the working area of the process located in east China.

Stratum. The main stratum in the study region is developed in Paleozonic earthem, Mesozoic earthem in the second place.

Magmatic Rock. Intrusive Rocks. The intrusive rock is well developed and can be divided into mafic rock and intermediate-acid intrusive rocks according to the characters and the types of forming .

Volcanic Rock. Volcanic rock is very developed in the researching region and occupied $30 \%$ or so, where the main activity is in Meso-Cenozoic. The Volcanoes erupt mainly from the center, composite volcano and volcanic rocks. Volcano and magmatic rock belt have close connection with forming gold mine.

Structure. This region experienced ancient Asia and approching Pacific Ocean structural region, which led the geologic construction be very complex and formed different structural trackways, they were different grade faults, folds .

Faults. The Regional faults in studying region mainly divided into northeast and northwest fault, they controlled the structure of mines and mountain range of sub-volcanoes respectively and the former cut through the later, which indicate the generation sequence of the two. The main faults are Chunyang, located in the big fault belt of the northwest of Wangqing, Laoheishan, located in the big fault belt of 
the northeast of Yanji and Wudaogou, located in the fault belt of northeast of Chunhua, those faults play a controlling role in the formation of precious minerals and polymetallic ore.

Chunyang, the big fault belt of the northwest of Wangqing, located in the Chunyang to Wangqing to Hunchun line of Wangqing Town, the character of which is thrust composed of a series of compressive fracture and compressive rupture zone together with two parallel faults, control the basic rocks and intermediate-acid intrusive rocks of Mesozoic basin, sedimentary formation and Meso-Cenozoic, the whole tendency of the belt is about 310 to 320 degree.

Laoheishan, the big fault belt of the northeast of Yanji, located in Laoheishan town, Mudanjiang City of Heilongjiang Province from the north end, cross Fuxing Town, Shiyan Town and Yanji City then extend to Helong City from the direction of southwest and covered by basin of cretaceous period in the southwest. The working area is made up of a series of faults with the length $90 \mathrm{~km}$ and the tendency of 30 to 40 degree. The surface of faults incline to south of east with the dip of 75 to 80 degree and is high-angle thrusts from southeast to northwest judged by scratches and steps.

Fold Structure. The structure of folds in researching area were protected incompletely for the bad effect of volcano activities, thus whose tracks can't obviously show the structural characters. Superposed basin in Mesozoic era is characterized by broad, gentle slope and synsedimentary monocline structure. The main fold structures are Wudaogou syncline and Xiaopanling anticline.

\section{Typical Mineral Deposit}

It is obvious to know that the formation of gold-copper mine and the activities of volcano have close relation by research. Formation of mine deposit can be divided into three typies, they are gold-silver mine of volcano rock, gold-silver-copper mine of volcano and sub-volcano rock and gold-copper mine of sub-volcano rock.

\section{Analysis on the Conditions of the Mine's Formation}

The typical mineral deposit and geological factors indicate that the geotectonic units and structure, magmatic rock, stratum, geochemical field and other geological conditions play an important role in the forming and protecting of precious Polymetallic mines.

The Relation of Geotectonic Units and the Formation of Mines. The researching region lies in a district of geotectonic units of Jilin Province, among two depressions and one uplift, different units is separated by regional big fault belts. The uplift is named by Mudanling-Chunhua belt and extends from east to west with length $200 \mathrm{~km}$ and width $50 \mathrm{~km}$ or so. The south and the north area are Xinhe-Madida and Dunhua-Duhuangzi fault belt respectively. At present, the known precious Polymetallic mines distribute in the finite range of uplift belt, which prove the close relationship between geotectonic units and the formation of mines.

The Relation of Fault Structure and Gold-copper Mine. The close relation of fault structure and gold-copper mine could be direct and indirect.

(1)The indirect controlling role on mine deposit of fault manifested as the controlling on the intrusive and erupting activities of magma.

(2)The direct controlling role on mine deposit of fault

The direction of mineral belt are east-to-west, north-to-east and north-to-west, which display the distribution regulations are two belts, three rows and four columns, concretely speaking, east-west be belts, north-east be rows, north-west be columns.

Ore-containing fault has Pleiotropia, among the directions of north-to-west, south-to-west and north-to-east, the last one in the main. The direction of ore-containing fault have something to do with region, the west part of researching area is north-to-west and north-to east, such as Xiaoxinan and Nongping gold mines the former direction, Ciweigou the later direction respectively.

Relation of Stratum and Gold-copper Mine. The relation of the stratum appeared in different period and the activity of gold-copper mine's formation is obvious, where the mineral deposit of in 
Hanwu-Aotao cover $62 \%$, mines appeared in every stratum of Permian system cover $0.02 \%$ and stratum in Daxinggou groups of Triassic cover $0.04 \%$.

Relation of Intrusive Rocks and Gold-copper Mine. Frequent strong activities of rock intrusive in studying area formed different intrusive rocks in property, range and size. The research on the distribution, Rock mineralization, microelement and other factors of intrusive rocks just show the relation of intrusive rocks and gold-copper mine.

Special relation of rock mass and mineralization

The intrusive activities of magma distribute almost from west

To east affected by the structure of studying area. The mineral belt composed by known mineral deposit and main elements anomalies attribute from east to west, rock with circula distribution formed the formation center on the rock mass in Baicaogou and snow belt.

The lithology is not the same in the east and west of studying area, where basic rock and acid rock are main respectively.

The main intrusive body is surrounding rocks, which shows that the being of ore happened after the activities of relative magma. The isotope age of ore-bearing rock bodies in Nongping gold mine are the range from 120.73 to $157.27 \mathrm{Ma}$ by $\mathrm{K}$-Ar assay method and $130 \mathrm{Ma}$ by $\mathrm{Rb}-\mathrm{Sr}$ assay method respectively. The specific forming time of the ore may be late Yanshanian epoch by the synthetic information of ores.

Relation of Geochemical Field and Gold-copper mine. The anomalies distribution of element of geochemical field in known gold-copper mineral deposit and mineralization has outstanding corresponding relation, which distribute in high element geochemical background.

The corresponding relationship indicates element of geochemical field is the main factor in the forming of mines.

\section{Comprehensive Prospecting Model for the Type of Volcano Rock Gold-copper Deposit in Eastern Yanbian, Jilin Province}

Object and Grade of Prospecting. In the above research, we know the types of deposit are volcano rock, subvolcano rock and volcano-subvolcano rock, where the first kind is the main. The precision of the data what we use is $1 / 250,000$. Taking the deposit of Ciweigou gold-silver, Xiaoxinan gold, Nongping gold and Naozhi gold-silver-copper as typical targets, the deposit's model is identified as the deposit level.

Synthetic Information of the Ore-prospecting Model for Gold-copper in the East of Yanbian. Analyzing the characters of the data by geological, geochemical and geophysical exploration, focusing on gold-copper deposit, we establish the relative geological, geochemical and geophysical description models.

Taking into consideration of all the gold-copper ore-controlling conditions, we have constructed the comprehensive information of the ore- prospecting model for gold-copper in the east of Yanbian with various types of information, and explored the relationship between the various types of associated information.

Geological Information of Controlling Ore

(1) Stratum. The stratum is composed of Xiangfangzi rock system of Hanwu system-Aotao system, Yangjingou and Madida rock system and so on. Further contains the stratums belonging to upper Permian, Daxinggou group of upper Triassic, Tuntianying group of Jurassic and Quanshui county group of Cretaceous.

(2) Structure. Fracture Intersection: Intersection of shell fractures, shell and ordinary fracture. Most host fracture structure is, where the main direction is N-W, the S-N and N-E in the second place.

Mineralization Information: The known deposit (points), mineralization and could be precious metals and multi-metal mineralization.

Surrounding Rocks Alternation: Main types are silication, pyritization, sericitization and calcium carbonate calcification. 
Based on the geographical environment of the gold-copper mine's formation in eastern region of Yanbian, the controlling conditions and laws and combined with the analysis of the related geochemical data, this study established the comprehensive prospecting model for the locating of gold-copper deposit, which will provide a theoretical basis for predicting the gold-copper deposit, and is of great meanings in assessing mineral resources in the future.

\section{References}

[1] Wang Shi-yuan, FAN Ji-zhang, Liu Ya-jian, et al. Application of geophysical methods in exploration of Xiao shiren gold deposit Jiangyuan, Jilin, China [J]. Geological Bulletin of China, 2007, 26(7): 909-915.

[2] Guan Jian. Study on metalogenetic law of precious and nonferrous deposits in the southeast part of Jilin Province: Ph. D dissertation [D].Changchun: Jilin University, 2004.

[3] Wang Shi-cheng, Cheng Qiu-ming, Fan Ji-zhang, et al. Gold ore resources synthesis information appraisal method [M]. Changchun: Jilin Science and Technology Publishing House, 1990: 10-12.

[4] Chen Chang yong, Li Shou yi, FAN Ji-zhang, et al. The synthetic informational prospecting models of metallogenetic series of gold, silver, copper lead and zincing the northern border land of North China massif[J].World Geology,1999,18(1):25-31.

[5] Saager R,M eyer M, Muffe R. Gold distribution in supracrustal rocks from Archean greenstone belts of southern Africa and from Palaeozoicultram afic complexes of the European Apls: metallogenetic and geochemical mipications [J].Econ G eo,1982,77:1-24. 